\title{
Urinary microRNA can be concentrated, dried on membranes and stored at room temperature in vacuum bags
}

Fanshuang Zhang, Xiaoyu Cheng, Yuan Yuan, Jianqiang Wu, Youhe Gao

Urine accumulates traces of changes that occur in the body and can potentially serve as a better biomarker source. Urinary microRNA is a promising class of non-invasive disease biomarkers. However, long-term frozen human urine samples are not a good source for the extraction of urinary microRNA. In this paper, we demonstrate that urinary microRNA can be concentrated, dried on membranes and stored in vacuum bags at room temperature for several months. The amount of total RNA on the membranes after storage at room temperature for three months was unchanged. The levels of miR-16 and miR-21 exhibited no significant differences ( $P=0.564,0.386$ ). This simple and economical method makes the large-scale storage of clinical samples of urinary microRNA or other nucleic acids possible. 
1 Urinary microRNA can be concentrated, dried on membranes and stored at room

2 temperature in vacuum bags

3 Fanshuang Zhanga, Xiaoyu Chenga , Yuan Yuan ${ }^{\mathrm{a}}$, Jianqiang $\mathrm{Wu}^{\mathrm{a}}$, Youhe Gao ${ }^{\mathrm{a}, \mathrm{b}, *}$

4 a Department of Pathophysiology, National Key Laboratory of Medical Molecular Biology,

5 Institute of Basic Medical Sciences Chinese Academy of Medical Sciences / School of Basic

6 Medicine Peking Union Medical College, Beijing 100005, China

7 b Department of Biochemistry and Molecular Biology, Beijing Normal University, Gene

8 Engineering and Biotechnology Beijing Key Laboratory, Beijing, 100875, P. R. of China

$9 *$ Corresponding author

10 Email: gaoyouhe@bnu.edu.cn

11 Tel: 86-10-69156407 


\section{Introduction}

The fundamental property of a biomarker is change. Whereas plasma typically maintains a homeostatic internal environment, urine tends to reflect changes occurring inside the body. This property potentially makes urine a better biomarker source than plasma (Gao 2013; Li et al. 2014). In addition, urine can be obtained in large quantities using non-invasive procedures, and various components of urine are relatively stable given that they have been incubated in the bladder at $37^{\circ} \mathrm{C}$ for several hours.

Changes in nucleic acids are a promising biomarker for diagnoses, prediction and monitoring of diseases (Ralla et al. 2014; Veltri \& Makarov 2006). MicroRNA, which belongs to the class of small non-coding RNAs, functions by base-pairing with mRNA molecules, thereby resulting in the silencing of these mRNAs (Bartel 2004). Currently, 1193 precursors and 1915 mature microRNA sequences have been reported in mice (miRBase 21.0). Similarly, there are 1881 precursors and 2588 mature microRNA sequences have been reported for humans (miRBase 21.0). MicroRNA has no known post-processing modifications; thus, the composition is less complex than other biomolecules (Weber et al. 2010). For this reason, microRNA is a promising new disease biomarker for ailments, such as malignancies of the prostate, bladder and kidney as well as other urologic diseases, which have already been extensively studied and reviewed. (Catto et al. 2011; Mlcochova et al. 2014; Ralla et al. 2014; Yang et al. 2013; Zhang et al. 2014). The preservation of urinary microRNA is the foundation of the application of urinary microRNA as the biomarker sources for the diseases diagnosis. In 2013, the stability of microRNAs in urine and urine storage conditions were evaluated by Mall et al., and this study demonstrated that microRNA 
33 was relatively stable in the harsh urinary environment, even at varied temperatures and after ten

34 freeze-thaw cycles (Mall et al. 2013). However, the median total RNA concentration of urine is

$3594 \mu \mathrm{g} / \mathrm{L}$ (with 129 interquartile range) in contrast to concentrations of $308 \mu \mathrm{g} / \mathrm{L}$ (with 104

36 interquartile range) in plasma and $47240 \mu \mathrm{g} / \mathrm{L}$ (with 73180 interquartile range) in breast milk

37 (Weber et al. 2010).

38 Recently, a new type of commercial urine preservation tube was invented for the preservation

39 of urine samples. However, the tubes are quite expensive, and this simple preservation method

40 without concentration requires a significant amount of space. Jia et al. introduced a method for

41 directly adsorbing urinary proteins onto polyvinylidene difluoride (PVDF) membranes that can be

42 subsequently dried and stored; however, other urinary components were not considered (Jia et al.

43 2014). Based on this method, an alternative nylon membrane, which exhibits stronger binding

44 affinities for nucleic acids including DNA and RNA via electrostatic interaction, was assessed for

45 its ability to concentrate and preserve urinary microRNA.

46 Materials and Methods

47 1. Ethics Statement

48 The purpose of this paper is to examine the use of nylon membranes to preserve and 49 concentrate urinary nucleic acids. Collecting urine does not harm the donor at all. Instead of using 50 individual urine samples, mixed urine samples were used in this study, so personal information 51 did not documented. The specimens were collected after obtaining verbal informed consent from 52 the participants or written consent from the participants who were willing to sign. The consent procedure including verbal or written consent and research protocol were approved by the Institute 
of Basic Medical Sciences Medical Ethics Committee of Peking Union Medical College (Project No. 040-2014). All of the records of consent by the participants were documented on laboratory notebook by the authors.

2. Urine collection

Urine samples from 10 healthy participants were collected and stored at $4^{\circ} \mathrm{C}$ and subsequently combined. All of the urine samples were centrifuged at $5,000 \times \mathrm{g}$ for $30 \mathrm{~min}$ at $4^{\circ} \mathrm{C}$. The supernatant was aliquoted into $50 \mathrm{~mL}$ sample tubes and stored at $-80^{\circ} \mathrm{C}$ until use. The participants included four males and six females ranging from 24 to 30 years in age.

3. Urinary nucleic acids preservation on the membranes

The experimental procedure was performed as described by Jia et al. with modifications (Jia et al. 2014). In Step 1, the 0.45- $\mu \mathrm{m}$ Positively-Charged Nylon 6,6 membranes (Cat\# BNBZF810S, Pall, NY) and the medium-speed qualitative filter papers were cut according to the diameter of the vacuum suction filter bottle (10 $\mathrm{cm}^{2}$ filter area). In Step 2, three to four sheets of wet filter paper were placed onto the vacuum suction filter bottle, and one wet nylon membrane was placed immediately onto the filter papers to avoid the generation of bubbles. In Step 3, the vacuum suction filter bottle was installed and connected to the vacuum pump. In Step 4, the collecting bottle was then loaded with urine supernatant. In Step 5, the vacuum pump was opened to allow the urine to pass through the nylon membrane in a drop-wise fashion. In Step 6, the intensity of the vacuum pressure was set to approximately $5 \mathrm{kPa}$ with an initial velocity of approximately 1 to 2 drops per second. As time passed, the speed of the drops was reduced, so a higher intensity vacuum pressure was required. The total filtration process time was 5 to $10 \mathrm{~min}$, and the intensity of the vacuum 
75 pressure was 5 to $50 \mathrm{kPa}$, depending on the volume of the urine. In Step 7, after the urinary nucleic

76 acids were adsorbed onto the nylon membranes, the membranes were placed into the $56^{\circ} \mathrm{C}$ drying

77 oven for 3 to $5 \mathrm{~min}$ to complete the drying process or left to dry at room temperature. In Step 8,

78 the dry membranes were placed between aseptic sealing bags and then sealed using a vacuum

79 sealer. Tags were added to the dry membranes that contained the basic information on the

80 participants and the unique number of the membranes, which could be cross-referenced with

81 additional information relevant to the urine sample. Finally, the membranes were stored at $-80^{\circ} \mathrm{C}$

82 or room temperature. A flow chart explaining the process is presented in Figure 1.

83

\section{Urinary RNA extraction}

RNA is more labile than DNA and because ribonuclease (RNase) is known to be present in the body fluids (Reddi \& Holland 1976; Zhao et al. 2014). Consequently, RNA molecules on the urinary nucleic acid-bound dry membranes were examined in this paper.

The urinary nucleic acid-bound dry membranes were cut into small pieces and placed in clean tubes. Total RNA, including microRNAs, was extracted by using TRIzol reagent (Invitrogen, Carlsbad, CA) according to the manufacturer's instructions. Briefly, $250 \mu \mathrm{L}$ of chloroform was added, and the samples were shaken vigorously for $15 \mathrm{sec}$. Then, the samples were centrifuged at $12,000 \mathrm{rpm}$ for $15 \mathrm{~min}$ at $4^{\circ} \mathrm{C}$. The fraction from the top aqueous phase was obtained and transferred into new $1.5-\mathrm{mL}$ tubes. Next, $600 \mu \mathrm{L}$ of isopropanol was added, and the solution was centrifuged for $15 \mathrm{~min}$ at $12,000 \mathrm{rpm}$ at $4^{\circ} \mathrm{C}$. After removing the aqueous solution, $1 \mathrm{~mL}$ of $75 \%$ ethanol was added, and the sample was centrifuged for $10 \mathrm{~min}$ at $12,000 \mathrm{rpm}$ at $4^{\circ} \mathrm{C}$. After removing the ethanol, the pellet was dissolved in RNase-free water and quantified with a 
96 NanoDrop spectrophotometer (Thermo Fisher Scientific). Finally, the sample was stored at $-80^{\circ} \mathrm{C}$

97 for further analysis by RT-qPCR.

98 5. MicroRNA quality control

99 The quality of the microRNA was evaluated on a Bioanalyzer 2100 instrument (Agilent,

100 Santa Clara, CA, USA) using small RNA kit.

101 6. Reverse transcription of urinary microRNA

102 U6, miR-16 and miR-21 were reverse transcribed using synthetic primers and the Promega

103 GoScript ${ }^{\mathrm{TM}}$ Reverse Transcription kit (Promega Corporation, Madison, USA) according to the

104 manufacturer's protocol. After combining the experimental primers with an equal amount of

105 template RNA, the primers and template mix were thermally denatured at $70^{\circ} \mathrm{C}$ for $5 \mathrm{~min}$ and

106 chilled on ice for $5 \mathrm{~min}$. The primers and template mix were added to the reaction mix on ice.

107 Following an initial annealing at $25^{\circ} \mathrm{C}$ for $5 \mathrm{~min}$, the reaction was incubated at $42^{\circ} \mathrm{C}$ for up to one

108 hour. Then, the reaction was incubated in a controlled-temperature heat block at $70^{\circ} \mathrm{C}$ for $15 \mathrm{~min}$.

109 The reaction product was placed on ice or stored at $-20^{\circ} \mathrm{C}$ until use.

110 7. Real-time PCR of urinary microRNA

111 To quantify urinary microRNA, real-time PCR amplification was performed in a $20-\mu 1$

112 reaction volume on a Bio-Rad real-time PCR system according to the manufacturer's protocols.

113 The real-time PCR reactions were set up in triplicate in 8-tube PCR strips (AXYGEN, Union City,

114 CA 94587 USA) and briefly centrifuged. Real-time PCR conditions included one cycle of initial

115 activation for $10 \mathrm{~min}$ at $95^{\circ} \mathrm{C}$ followed by 40 cycles of denaturation for $15 \mathrm{sec}$ at $95^{\circ} \mathrm{C}$, annealing

116 for $10 \mathrm{sec}$ at $95^{\circ} \mathrm{C}$ and extension for $30 \mathrm{sec}$ at $55^{\circ} \mathrm{C}$. The melting program was performed at $55^{\circ} \mathrm{C}$ 
117 to $94.5^{\circ} \mathrm{C}$ at a heating rate of $1^{\circ} \mathrm{C}$ per $5 \mathrm{sec}$. The levels of the target microRNAs were normalized 118 using U6, and the relative level of microRNA was determined using the $\Delta \Delta \mathrm{Ct}$ method. All of the 119 samples were tested in triplicate.

120 8. Statistical analysis

All statistical analysis was performed with the SPSS software (version 16, IBM), and all tests were two-sided with a 0.05 significance level. The total RNA amounts on the membranes before and after three months of storage at room temperature were compared using t-tests. The $\mathrm{C}_{\mathrm{T}}$ values of microRNA before and after three months of storage at room temperature were compared using Mann-Whitney $\mathrm{U}$ tests to account for differences in variance between groups.

\section{Results}

1. Loading capacity of the nylon membranes

Centrifuged urine $(100 \mathrm{~mL})$ was filtered through a $10-\mathrm{cm}^{2}$ nylon membrane, which adsorbs urinary nucleic acids by electrostatic interaction, and the filtrates were then filtered through a new

nylon membrane to detect urinary nucleic acids not adsorbed by the first membrane. The urinary nucleic acid-bound membranes were dried completely in a $56^{\circ} \mathrm{C}$ drying oven, and RNA was extracted and quantified. Experiments repeated in triplicate indicated that the average amount of RNA extracted from the first nylon membrane was $4442.1667 \pm 333 \mathrm{ng}$, whereas $759.1 \pm 21.83$ ng of RNA was extracted from the second nylon membrane. A comparison of the nucleic acid adsorption amounts from the first and second membranes revealed that most of the RNA was adsorbed on the first membrane. The binding rate of urinary RNA was $85.41 \%$ [4442/(4442+759)]. 
The adsorption of $50 \mathrm{~mL}$ of mixed centrifuged urine on $10 \mathrm{~cm}^{2}$ nylon membrane was repeated

7 times. Then, the membranes were placed into the $56^{\circ} \mathrm{C}$ drying oven for 5 min to complete the drying process. The total RNA that was adsorbed onto each nylon membrane was extracted and quantified with a NanoDrop spectrophotometer. As shown in Table 1, the average amount of total RNA from 7 repeats was $7788.65 \pm 145.9 \mathrm{ng}$, and the coefficient of variation was 0.0187 .

3. The amount of urinary microRNA stored at room temperature for three months was unchanged Adsorption of $100 \mathrm{~mL}$ of mixed centrifuged urine on $10 \mathrm{~cm}^{2}$ nylon membranes was repeated 8 times. Then, the membranes were placed into the $56^{\circ} \mathrm{C}$ drying oven for $5 \mathrm{~min}$ to complete the drying process. Four sheets of membranes were chosen randomly, and total RNA adsorbed onto the nylon membranes was extracted and quantified using a NanoDrop spectrophotometer (Table 2). The other four membranes were stored at room temperature for approximately 3 months. Total RNA adsorbed onto the nylon membranes was then extracted and quantified with a NanoDrop spectrophotometer (Table 2). The average amount of the total RNA from 4 independent experiments from membranes before room temperature storage was $11264.70 \pm 666.23 \mathrm{ng}$, and the coefficient of variation was 0.0232 . The average amount of total RNA after 3 months room temperature storage was $11920.73 \pm 766.56 \mathrm{ng}$, and the coefficient of variation was 0.0219 . No significant difference was observed before and after storage $(\mathrm{P}=0.244)$. MicroRNA quality stored at room temperature for three months was unchanged (Figure. 2). U6, miR-16 and miR-21 were also quantified by qRT-PCR as described in the 'Materials \& Methods' section. Relative $\mathrm{C}_{\mathrm{T}}$ values were proportional to urinary microRNA quantity (Mall et al. 2013), and U6 was reported as an internal normalization control (Mlcochova et al. 2014). Our data indicate that U6 was detectable 
159 in the urine of all of the 8 samples, and no significant difference in $\mathrm{C}_{\mathrm{T}}$ values $(\mathrm{P}=1.000)$ was 160 observed before and after storage. Additionally, the miR-16 and miR-21 $\mathrm{C}_{\mathrm{T}}$ values did not 161 significantly differ before and after storage (Figure. 3).

162

163

164

\section{Discussion}

MicroRNA has been proposed as a promising class of biomarkers (Kroh et al. 2010; Mall et al. 2013; Mitchell et al. 2008). This study exclusively examined total RNA and microRNA levels on the urinary nucleic acid-bound membranes.

Although it has not been widely used until recently, urinary DNA is a potential source of material for molecular diagnosis (Chan et al. 2003; Goessl et al. 2000; Zhang et al. 1999). However, the storage of fresh urine at temperatures of $4^{\circ} \mathrm{C}$ or lower results in significant DNA degradation (Hilhorst et al. 2013; Yokota et al. 1998). To overcome this disadvantage, a magnetic bead-based method was developed for extracting and concentrating DNA from urine (Bordelon et al. 2013). However, this method only utilizes samples of urine up to $5 \mathrm{~mL}$, and an increase in volume to as high as $20 \mathrm{~mL}$ may require a longer adsorption step (Bordelon et al. 2013). According to the property described by the company or other articles (Kainz et al. 1989; Khandjian 1986; Taylor 1985; Thurston \& Saffer 1989), "It offers high sensitivity in nucleic acid detection applications. The binding mechanism for membrane is through electrostatic interactions" (http://www.pall.com/main/oem-materials-and-devices/product.page?lid=gri78lty). All kinds of nucleic acids including DNA and RNA can all be bound on membranes. Based on this, we proposed that the method can also be used for DNA concentration and preservation too. What's more, these urinary nucleic acid-bound dry membranes may be stored considerably longer than 
three months.

$$
\text { Generally, } 200 \mu \mathrm{L} \text { or } 400 \mu \mathrm{L} \text { fresh urine will be used for each RNA extraction. Because of the }
$$
low concentration of urinary RNA, it often costs several extractions to have enough RNA for reverse transcription. The method described here provides an economical way to concentrate and preserve urinary RNA. Different urine samples may have different amount of RNA on the membrane. However, no matter how much RNA could be recovered, as long as the amount of templates used for PCR reaction remained the same, the target microRNAs can still be quantified and compared.

Urine is a better source for biomarker research (Gao 2013). The current study was the first to report the use of nylon membranes to concentrate and preserve urinary nucleic acids. The nucleic acids preserved on nylon membranes could be extracted and subsequently analyzed using traditional downstream analytical applications, such as PCR, real time PCR, nucleic acid microarray or other nucleic acid test methods. This method allows for the preservation of urine samples from all consenting patients during every stage of disease development or even for those consenting healthy individuals for prospective studies.

\section{References}

Bartel DP. 2004. MicroRNAs: genomics, biogenesis, mechanism, and function. Cell 116:281-297.

Bordelon H, Russ PK, Wright DW, and Haselton FR. 2013. A magnetic bead-based method for concentrating DNA from human urine for downstream detection. PLOS one 8:e68369.

Catto JW, Alcaraz A, Bjartell AS, De Vere White R, Evans CP, Fussel S, Hamdy FC, Kallioniemi O, Mengual L, Schlomm T, and Visakorpi T. 2011. MicroRNA in prostate, bladder, and kidney cancer: a systematic review. Eur Urol 59:671-681.

Chan AK, Chiu RW, Lo YM, and Clinical Sciences Reviews Committee of the Association of Clinical B. 2003. Cell-free nucleic acids in plasma, serum and urine: a new tool in molecular diagnosis. Ann Clin Biochem 40:122-130. Gao Y. 2013. Urine-an untapped goldmine for biomarker discovery? Sci China Life Sci 56:1145-1146. 
Goessl C, Krause H, Muller M, Heicappell R, Schrader M, Sachsinger J, and Miller K. 2000. Fluorescent methylationspecific polymerase chain reaction for DNA-based detection of prostate cancer in bodily fluids. Cancer Res 60:5941-5945.

Hilhorst M, Theunissen R, van Rie H, van Paassen P, and Tervaert JW. 2013. DNA extraction from long-term stored urine. BMC Nephrol 14:238.

Jia L, Liu X, Liu L, Li M, and Gao Y. 2014. Urimem, a membrane that can store urinary proteins simply and economically, makes the large-scale storage of clinical samples possible. Sci China Life Sci 57:336-339.

Kainz P, Seifriedsberger M, and Strack HB. 1989. A modified primer extension procedure for specific detection of DNA-RNA hybrids on nylon membranes. Anal Biochem 179:366-370.

Khandjian EW. 1986. UV crosslinking of RNA to nylon membrane enhances hybridization signals. Mol Biol Rep 11:107-115.

Kroh EM, Parkin RK, Mitchell PS, and Tewari M. 2010. Analysis of circulating microRNA biomarkers in plasma and serum using quantitative reverse transcription-PCR (qRT-PCR). Methods 50:298-301.

Li M, Zhao M, and Gao Y. 2014. Changes of proteins induced by anticoagulants can be more sensitively detected in urine than in plasma. Sci China Life Sci 57:649-656.

Mall C, Rocke DM, Durbin-Johnson B, and Weiss RH. 2013. Stability of miRNA in human urine supports its biomarker potential. Biomark Med 7:623-631.

Mitchell PS, Parkin RK, Kroh EM, Fritz BR, Wyman SK, Pogosova-Agadjanyan EL, Peterson A, Noteboom J, O'Briant KC, Allen A, Lin DW, Urban N, Drescher CW, Knudsen BS, Stirewalt DL, Gentleman R, Vessella RL, Nelson PS, Martin DB, and Tewari M. 2008. Circulating microRNAs as stable blood-based markers for cancer detection. Proc Natl Acad Sci U S A 105:10513-10518.

Mlcochova H, Hezova R, Stanik M, and Slaby O. 2014. Urine microRNAs as potential noninvasive biomarkers in urologic cancers. Urol Oncol 32:41 e41-49.

Ralla B, Stephan C, Meller S, Dietrich D, Kristiansen G, and Jung K. 2014. Nucleic acid-based biomarkers in body fluids of patients with urologic malignancies. Crit Rev Clin Lab Sci 51:200-231.

Reddi KK, and Holland JF. 1976. Elevated serum ribonuclease in patients with pancreatic cancer. Proc Natl Acad Sci U S A 73:2308-2310.

Taylor GR. 1985. Southern transfer of native DNA using nylon membranes. Anal Biochem 148:524-526.

Thurston SJ, and Saffer JD. 1989. Ultraviolet shadowing nucleic acids on nylon membranes. Anal Biochem 178:4142.

Veltri RW, and Makarov DV. 2006. Nucleic acid-based marker approaches to urologic cancers. Urol Oncol 24:510527.

Weber JA, Baxter DH, Zhang S, Huang DY, Huang KH, Lee MJ, Galas DJ, and Wang K. 2010. The microRNA spectrum in 12 body fluids. Clin Chem 56:1733-1741.

Yang Y, Xiao L, Li J, Kanwar YS, Liu F, and Sun L. 2013. Urine miRNAs: potential biomarkers for monitoring progression of early stages of diabetic nephropathy. Med Hypotheses 81:274-278.

Yokota M, Tatsumi N, Tsuda I, Takubo T, and Hiyoshi M. 1998. DNA extraction from human urinary sediment. J Clin Lab Anal 12:88-91.

Zhang DZ, Lau KM, Chan ES, Wang G, Szeto CC, Wong K, Choy RK, and Ng CF. 2014. Cell-free urinary microRNA-99a and microRNA-125b are diagnostic markers for the non-invasive screening of bladder cancer. PLOS one 9:e100793. 
246 Zhang J, Tong KL, Li PK, Chan AY, Yeung CK, Pang CC, Wong TY, Lee KC, and Lo YM. 1999. Presence of donor- and recipient-derived DNA in cell-free urine samples of renal transplantation recipients: urinary DNA chimerism. Clin Chem 45:1741-1746.

Zhao A, Peoc'h M, Cottier M, Genin C, Mottet N, and Li G. 2014. Cell-free RNA content in urine as a possible molecular diagnostic tool for clear cell renal cell carcinoma. Int J Cancer.

251 http://www.pall.com/main/oem-materials-and-devices/product.page?lid=gri78lty 
252

253

254

255

256

257

258

259

260

261

262

\section{Legends}

Figure 1. The scheme of microRNA concentration and preservation.

Figure 2. (A) gel electrophoresis analysis of small RNA fractions on an Agilent small RNA chip.

(B) fluorescence intensity of small RNA fractions at various sizes (nt). Lane 1 - 4 represented the membranes before 3 months storage. Lane 5 - 8 represented the membranes after 3 months storage.

Figure 3. Scatter plots of urinary levels of miR-16 (A) and miR-21 (B) in the before storage group $(n=4)$ and the after storage group $(n=4)$. MicroRNA levels (Log10 scale at Y-axis) were normalized to U6. The line represents the median value.

\section{Tables}

Table 1. Total amount of RNA

Table 2. Total amount of RNA before and after storage 
1

The scheme of microRNA concentration and preservation.

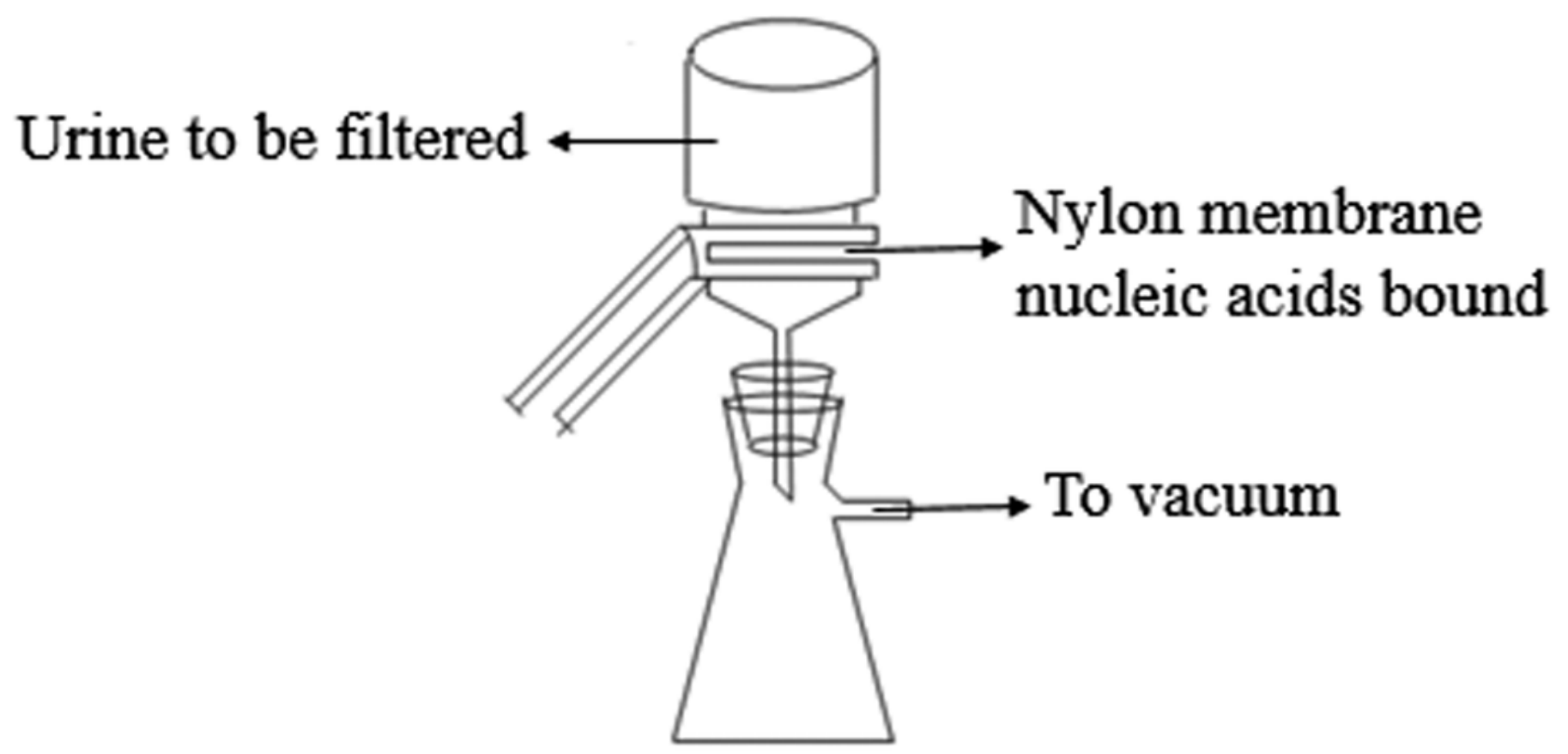


2

(A) gel electrophoresis analysis of small RNA fractions on an Agilent small RNA chip. (B) fluorescence intensity of small RNA fractions at various sizes (nt).

Lane 1 - 4 represented the membranes before 3 months storage. Lane 5 - 8 represented the membranes after 3 months storage. 

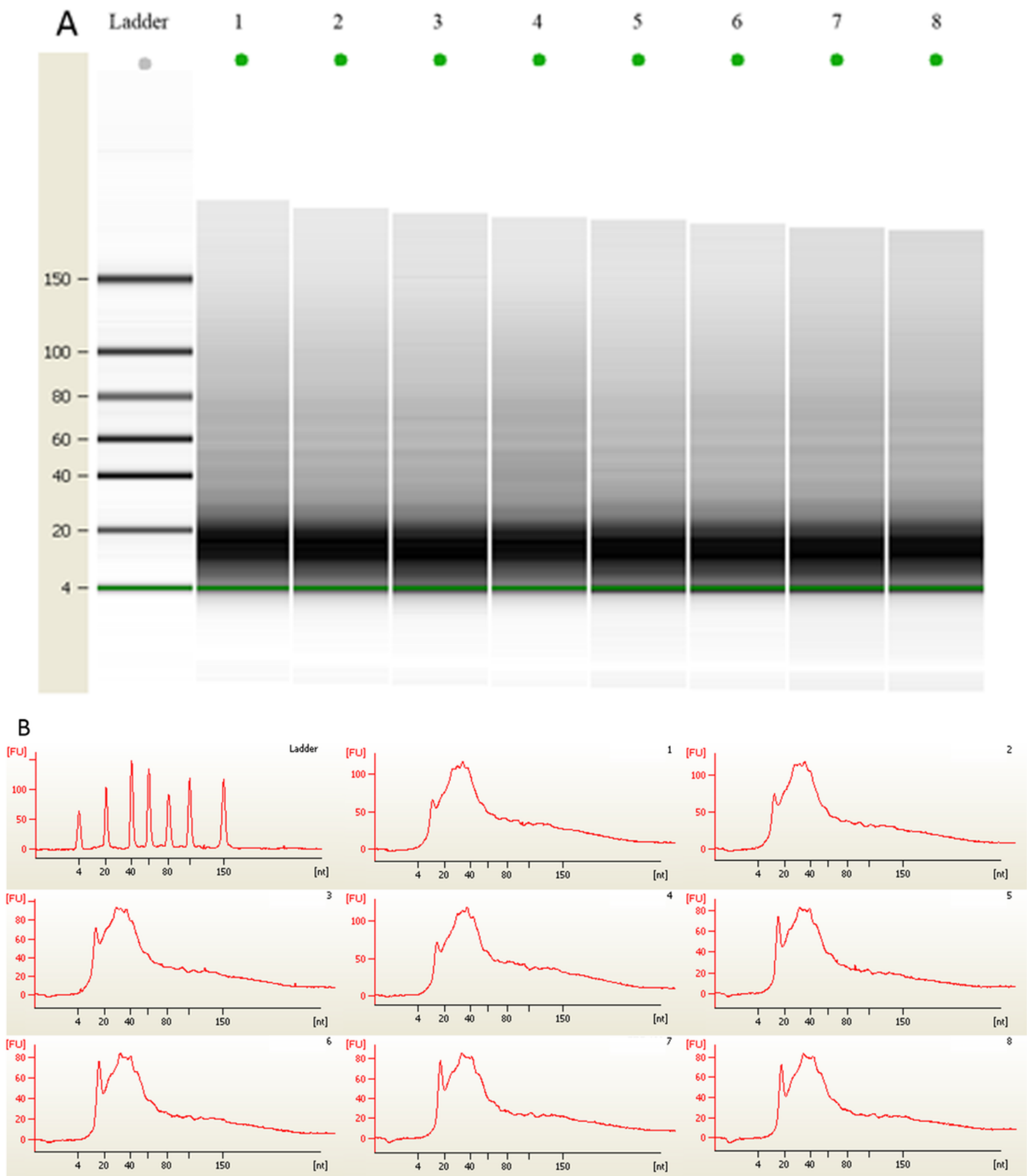
3

Scatter plots of urinary levels of miR-16 (A) and miR-21 (B) in the before storage group $(n=4)$ and the after storage group $(n=4)$.

MicroRNA levels (Log10 scale at Y-axis) were normalized to U6. The line represents the median value.
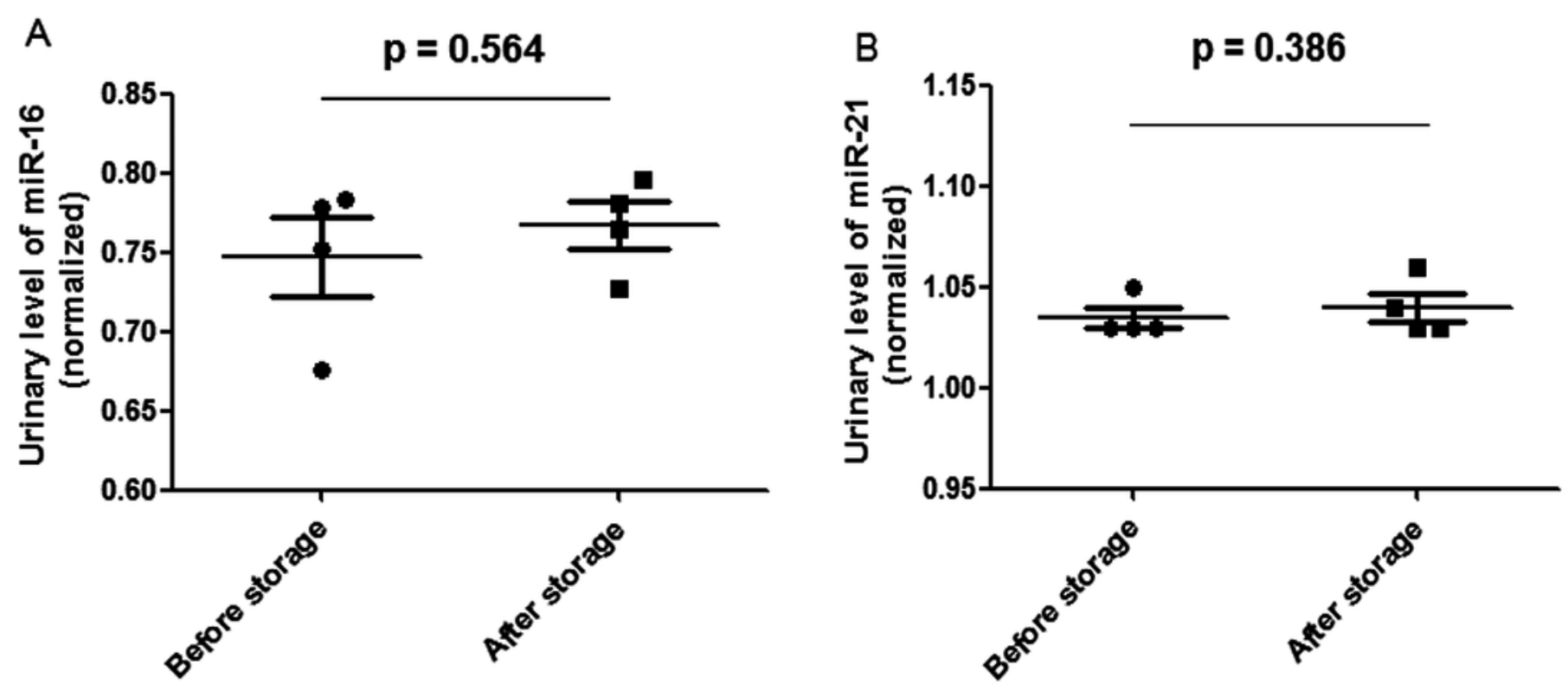


\section{Table 1 (on next page)}

Total amount of RNA 
2 Table 1. Total amount of RNA

\begin{tabular}{cc}
\hline NO. & $\begin{array}{c}\text { RNA amount, ng } \\
\text { (interquartile range) }\end{array}$ \\
\hline 1 & 7669.35 \\
2 & 7894.40 \\
3 & 7832.15 \\
4 & 7832.00 \\
5 & 7825.67 \\
6 & 7947.00 \\
7 & 7520.00 \\
\hline
\end{tabular}

3 


\section{Table 2 (on next page)}

Total amount of RNA before and after storage I 
2 Table 2. Total amount of RNA before and after storage

\begin{tabular}{llll}
\hline NO. & $\begin{array}{l}\text { RNA amount, ng } \\
\text { (before storage) }\end{array}$ & NO. & $\begin{array}{l}\text { RNA amount, ng } \\
\text { (after storage) }\end{array}$ \\
\hline 1 & 10853.10 & 5 & 11370.33 \\
2 & 11867.70 & 6 & 11173.53 \\
3 & 11793.60 & 7 & 12396.78 \\
4 & 10544.40 & 8 & 12742.29 \\
\hline
\end{tabular}

3 